\title{
Sistema automatizado de aquecimento solar para controle de fitopatógenos da água de irrigação
}

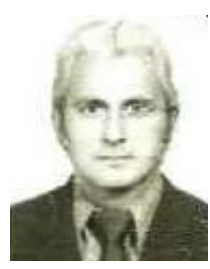

\author{
Carlos A. da S. Braga ${ }^{1}$, Geraldo Armond ${ }^{2}$, Maria A. de S. Tanaka ${ }^{3}$, Margarida F. Ito ${ }^{3}$, Cezar M. Mesquita ${ }^{4}$, \\ José V.G. Maziero², José A. Bernardi² \& Afonso Peche Filho² \\ 1 Centro de Mecanização e Automação Agrícola/IAC/SAA, Rod. D. Gabriel P.B. Couto km 65, CP 26, CEP 13201-970, \\ Jundiaí, SP. Fone: (11) 7392-8155. E-mail: braga@dea.iac.br (Foto) \\ ${ }^{2}$ Centro de Mecanização e Automação Agrícola/IAC/SAA \\ 3 Centro de Fitossanidade/IAC, CP 28, CEP 132001-970, Campinas, SP \\ ${ }^{4}$ EMBRAPA, CNPsoja. CP 321, CEP 86001-970, Londrina, PR
}

Protocolo 119 - 15/09/2000

\begin{abstract}
Resumo: O sistema automatizado de aquecimento solar, baseou-se em um processo misto de aquecimento da água em circuito fechado, através de coletores planos e dois princípios integrados de transmissão de calor, um por convecção natural e o outro por convecção forçada. A automatização foi realizada por monitores termostáticos diferenciais. Os testes normativos abrangeram as temperaturas programadas de 50,55 e $60^{\circ} \mathrm{C}$, que contemplam a faixa de temperatura letal para a maioria dos fitopatógenos. Os resultados indicaram rendimentos térmicos da ordem de 63, 55 e $52 \%$, superiores, quando comparados aos rendimentos médios de 50, 47 e $45 \%$ dos sistemas convencionais. Os resultados experimentais mostraram que o sistema é eficiente para a eliminação de patógenos da água de irrigação, sendo promissor como uma opção de baixo custo para ser usado em viveiros, casas-de-vegetação e pequenas ou médias propriedades agrícolas.
\end{abstract}

Palavras-chave: aquecimento solar automatizado, desinfestação solar da água

\section{Automatic solar heating system for control of pathogens in irrigation water}

\begin{abstract}
In the system proposed, which uses flat collectors, both natural and forced convection are responsible for the transfer of heat to the circulating water. The automation of the system is performed by thermostats, placed in different places, electrically connected to other components like valves and a water pump. Under identical test conditions and in the range of temperatures considered $\left(50,55\right.$ and $\left.60^{\circ} \mathrm{C}\right)$, which includes the reference lethal temperature range for pathogens, the thermal efficiencies attained were 63, 55 and 52\%, which compare favorably with those obtained in conventional systems, these being 50, 47 and $42 \%$ respectively, as reported. The results of the experimental trials show that the system described is a viable option to eliminate pathogens present in irrigation water, while its low cost makes it attractive for use in nurseries, greenhouses and on small farms.
\end{abstract}

Key words: solar heating, solar collectors, water disinfestation

\section{INTRODUÇÃO}

Por suas características de fonte renovável não poluidora, como insumo gratuito e abundante no Brasil, a valores médios anuais da ordem de $200 \mathrm{~W} \mathrm{~m}^{-2}$, a energia solar se impôs como área de interesse nacional, após a crise mundial do petróleo, em 1970. Projeções do Ministério das Minas e Energia (MME) para o ano 2000, estimavam uma participação ainda insignificante da energia solar no balanço energético do país, com indicadores de $0,1 \%$ do consumo total da energia primária (CNP, 1980).

A energia solar, com suas múltiplas utilizações diretas na geração de calor para processos térmicos, a baixa temperatura (inferior a $100^{\circ} \mathrm{C}$ ), nas áreas industrial, agrícola e doméstica, tem-se mostrado técnica e economicamente viável, em países do primeiro mundo (Palz, 1981).

Com relação ao Brasil, já se dispõe de tecnologias desenvolvidas em Centros de Pesquisa, que já estão sendo transferidas, principalmente ao meio rural, como fonte alternativa de calor no aquecimento da água para agroindústria, doméstico, aquecimento de ambientes, de estufas, de viveiros, secagem de produtos agrícolas, tratamento térmico de solos e outros (Bezerra, 1979; Roa, 1979; Macedo 1981; Armond et al., 1990). Na área de avaliação tecnológica de sistemas e componentes solares, destacam-se o IPEN - Instituto de Pesquisas Energéticas e Nucleares (Batista Filho, 1981), a Universidade Federal do Rio 
Grande do Sul (Kpenzinger \& Corbela, 1981) e a Associação Brasileira de Normas Técnicas (ABNT, 1981).

Macedo (1981) coordenando o grupo de Energia Solar do Departamento de Engenharia Mecânica da Universidade de Campinas (UNICAMP) realizou estudos e projetos com coletores solares para o aquecimento de ar e de água, acumuladores térmicos e superfícies seletivas absorvedoras, enquanto Armond et al. (1990) desenvolveram projetos na área de coletores solares planos, como fonte de calor para o tratamento térmico de solos no controle de patógenos. Por sua vez, Bezerra (1979) executou projetos de utilização prática da energia solar com coletores planos para aquecimento de água, uso doméstico e industrial, e Santos (1980) desenvolveu projetos de construção e avaliação de coletor armazenador de energia solar para secagem de produtos agrícolas .

Nas aplicações na agricultura, indústria e doméstica, o dispositivo básico de captação de energia solar é o coletor plano, para aquecimento do ar ou de líquidos, já convencional em todo o mundo e em uso na geração de calor, para diversos processos térmicos, a baixas calorias, cujos rendimentos térmicos apresentam valores médios da ordem de 45 a $50 \%$, quando operam na faixa de temperaturas de 50 a $60{ }^{\circ} \mathrm{C}$, sob radiação solar intensa (Lunde, 1980; Palz, 1981).

Este parâmetro referencial de temperatura, abrange, em equivalência, a faixa de temperaturas de 35 a $60^{\circ} \mathrm{C}$, letal para a maioria dos microrganismos fitopatogênicos (Wolf \& Wolf, 1947; Cochrane, 1958, Deveral, 1965). Os propágulos desses microrganismos na maioria fungos, podem ser transportados pela água de irrigação que, desta maneira, constitui-se em importante forma de disseminação de patógenos em viveiros e culturas irrigadas, tanto de frutíferas como de hortaliças, ornamentais e outras plantas (Grech \& Rijkenberg, 1992).

Dentro deste contexto e na busca de solução alternativa para a desinfestação da água utilizada para irrigação e outras finalidades agrícolas, o presente trabalho objetivou desenvolver um sistema automatizado de aquecimento solar da água, até uma temperatura letal para a maioria dos fitopatógenos presentes.

\section{MATERIAL E MÉTODOS}

Este trabalho foi conduzido nos Centros de Mecanização e Automação Agrícola - CMAA e de Fitossanidade, ambos do Instituto Agronômico de Campinas (IAC), durante os anos de 1998 e 1999. O sistema baseou-se em um processo de aquecimento solar da água, em circuito térmico fechado através de coletores planos, empregando-se dois princípios integrados de transmissão de calor, um por convecção natural e o outro por convecção forçada, ambos atuando como mecanismos de transferência de energia térmica gerada nos coletores à massa de água, neles circulando, até que esta atingisse a temperatura final programada de processamento.

A automatização do sistema foi obtida por monitores termostáticos diferenciais, interligados aos demais componentes, que monitoraram todas as operações do equipamento básico montado para os testes, de acordo com o esquema técnico apresentado na Figura 1.

O sistema foi avaliado por meio do equipamento básico (Figura 1) a fim de se comprovar seu rendimento térmico como

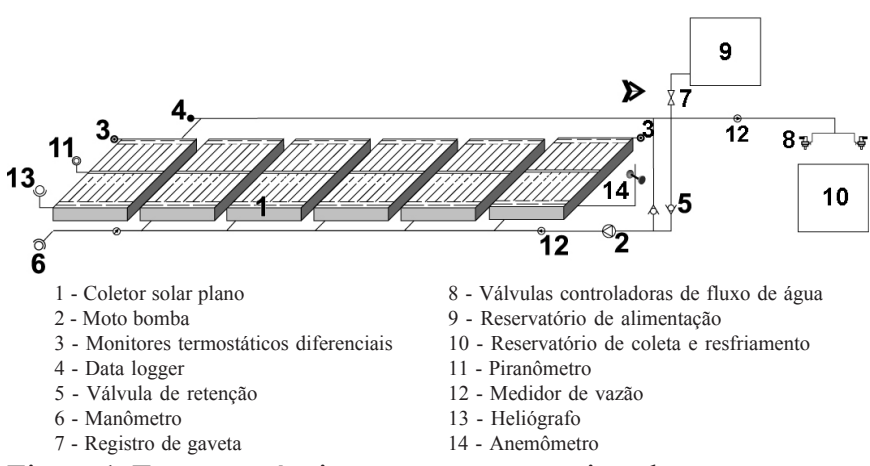

Figura 1. Esquema técnico para montagem, instalação e operação

do equipamento básico

fonte de calor para o tratamento térmico da água, usando-se o método de ensaio IPT(1981). Este método se baseou em testes normativos, conduzidos em função das temperaturas operacionais programadas de 50,55 e $60{ }^{\circ} \mathrm{C}$, as quais contemplaram a faixa referencial de temperatura de 35 a $60^{\circ} \mathrm{C}$ que, durante o tempo de $10 \mathrm{~min}$, é letal para a maioria dos microrganismos fitopatogênicos (Wolf \& Wolf, 1947; Cochrane, 1958; Deverall, 1965). Outrossim, a realização dos testes normativos com o equipamento básico envolveu quatro fases operacionais automatizadas descritas a seguir:

Fase 1: transferência da massa de água do reservatório de alimentação para os coletores solares;

Fase 2: preaquecimento da massa de água nos coletores solares, por processo de convecção natural, a partir da sua temperatura inicial $\left(\mathrm{T}_{\mathrm{i}}\right)$ no reservatório de alimentação (9) até a temperatura intermediária $\left(\mathrm{T}_{\mathrm{int}}\right)$ de acionamento da moto-bomba (2), programada no monitor termostático $\mathrm{Mt}_{1} \mathrm{D}(\mathrm{B})$ com o diferencial de $10^{\circ} \mathrm{C}$, relação de temperatura final $\left(\mathrm{T}_{\mathrm{f}}\right)$ de operação.

Fase 3: complementar a dinâmica de aquecimento da massa de água, por processo de convecção forçada, em circuito fechado, através dos coletores solares e induzida pela moto-bomba (2) a partir da temperatura intermediária $\left(\mathrm{T}_{\text {int }}\right)$, até a temperatura final de operação $\left(\mathrm{T}_{\mathrm{f}}\right)$ de processamento, programada no controlador termostático $\left(\mathrm{MT}_{2} \mathrm{D}\right)$;

Fase 4: descarga e carga simultâneas da massa de água, respectivamente, já processada (quente) dos coletores ao reservatório de coleta (10) e a processar (fria), do reservatório de alimentação (9) para coletores; operações comandadas pelo monitor termostático $\left(\mathrm{MT}_{2} \mathrm{D}\right)$ que também monitoriza as válvulas controladoras de fluxo de água no equipamento.

Durante os testes registraram-se, por meio de um Data Logger (4) de alta resolução, as temperaturas da massa de água nas seções de entrada, de saída e mediana dos coletores solares. Através de uma Estação Meteorológica automatizada, monitoraram-se os parâmetros climáticos, como radiação solar diária incidente no plano do coletor, velocidade do vento, temperatura e umidade relativa do ar ambiente.

O cálculo do rendimento térmico horário do sistema foi determinado pela Eq. (1) (Bezerra, 1979):

$$
\eta_{\mathrm{h}}=\frac{\mathrm{qu}}{\mathrm{HR}}
$$

na qual:

$\eta_{\mathrm{h}} \quad$ - rendimento térmico horário, $\%$ 
qu - energia útil coletada pelo sistema, $\mathrm{KJ} \mathrm{m}^{-2} \mathrm{~h}^{-1}$

$\mathrm{HR}$ - radiação solar incidente no plano do coletor, $\mathrm{KJ} \mathrm{m}^{-2} \mathrm{~h}^{-1}$

A energia útil (qu) disponível foi calculada usando-se a Eq. (2) (Bezerra, 1979):

$$
q u=m_{h} c\left(T_{f}-T_{i}\right)
$$

em que:

$\mathrm{m}_{\mathrm{h}} \quad$ - massa de água processada, $\mathrm{kg} \mathrm{m}^{-2} \mathrm{~h}^{-1}$

c - calor específico da água, $4,19 \mathrm{KJ} \mathrm{kg}^{-1}{ }^{\circ} \mathrm{C}^{-1}$

$\mathrm{T}_{\mathrm{f}} \quad$ - temperatura final média de processamento da água, ${ }^{\circ} \mathrm{C}$

$\mathrm{T}_{\mathrm{i}} \quad$ - temperatura inicial na seção de entrada do coletor, ${ }^{\circ} \mathrm{C}$

Com base na Eq. (2) determinou-se o tempo de exposição ( T exp) da massa de água no coletor solar, nas faixas de temperatura programada, parâmetro fundamental com vistas ao controle de fitopatógenos presentes na água de irrigação, usando-se a Eq. (3):

$$
\mathrm{T} \exp =\frac{\mathrm{CC}}{\mathrm{m}_{\min }}
$$

em que:

Texp - tempo de exposição ao calor, nas faixas de temperatura programada da massa de água de $\left(1,5 \mathrm{~kg} \mathrm{~m}^{-2}\right)$ correspondente à capacidade de carga do coletor solar plano

$\mathrm{m}_{\min }$ - massa de água processada no coletor solar em $\left(\mathrm{kg} \mathrm{m}^{-2} \min ^{-1}\right)$

O equipamento foi testado quanto à eficiência na eliminação de fungos patogênicos ao morangueiro (Botrytis cinerea, Colletotrichum fragariae, Fusarium sp. e Pythium sp.), ao quiabeiro (Verticillium dahliae), à alface (Rhizoctonia solani) e ao feijoeiro (Fusarium oxysporum $\mathrm{f}$. sp. phaseoli). O inóculo de cada fungo foi introduzido no sistema, de modo a promover a contaminação da água, e submetido às temperaturas programadas de 40 a $70{ }^{\circ} \mathrm{C}$, em intervalos de $5{ }^{\circ} \mathrm{C}$. Para verificar a sobrevivência dos patógenos após exposição a cada temperatura, alíquotas foram tomadas e levadas ao laboratório de Fitopatologia, onde foram colocadas, assepticamente, em placas de Petri contendo meio de cultura BDA (batata-dextrose-agar) e incubadas a $28{ }^{\circ} \mathrm{C}$. Foram considerados eficientes os tratamentos em que não houve nenhum crescimento do fungo após 7 a 10 dias de incubação.

\section{RESULTADOS E DISCUSSÃO}

Na Tabela 1 encontram-se os valores médios mensais dos parâmetros físicos, obtidos nos testes normativos (ABNT, 1981) e realizados no período representativo do ano, no qual as posições típicas de altitude e azimute do sol no seu movimento aparente foram favoráveis ao maior rendimento térmico do sistema de captação de energia solar (Palz, 1981).

Quanto ao aspecto fundamental da eficiência térmica do sistema testado como fonte alternativa de calor, são apresentados, na Tabela 1, os parâmetros térmicos de rendimento ( $\eta$ máximo, quando em operação na temperatura limite de $60{ }^{\circ} \mathrm{C}$; os valores obtidos são superiores ao rendimento térmico $(\eta)$ de $45 \%$ (média dos sistemas convencionais, operando nas mesmas condições de temperatura), citado por Palz (1981). Do ponto de vista de viabilidade técnica em relação ao uso do sistema desenvolvido no controle de fitopatógenos, são apresentados, na mesma Tabela, os resultados de rendimento térmico $(\eta)$ operacional nas três faixas de temperatura programada, as quais contemplaram a faixa de 35 a $60{ }^{\circ} \mathrm{C}$, letal para a maioria dos microrganismos fitopatogênicos, conforme a literatura consultada (Wolf \& Wolf, 1947; Cochrane, 1958; Deverall, 1965). Na Figura 2, constata-se que foram obtidos parâmetros de tempo de exposição da massa de água ao calor nos limites de tempo de $10 \mathrm{~min}$., durante o qual a permanência em cada uma das temperaturas acima mencionadas é considerada letal pelos citados autores.

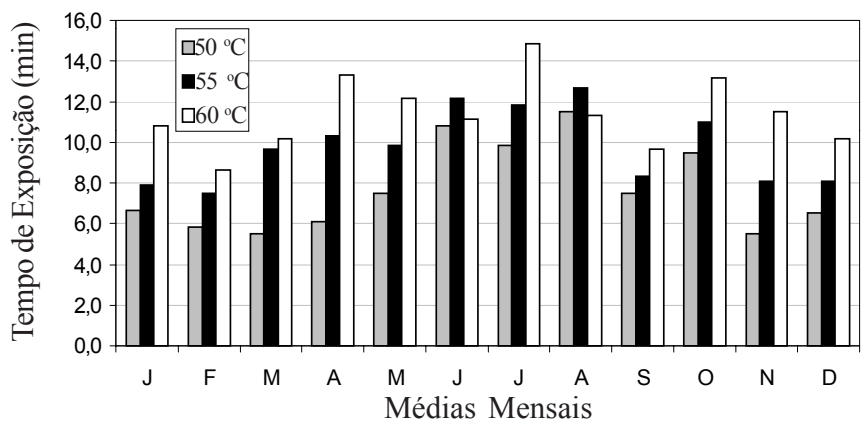

Figura 2. Tempo de exposição da massa de água $\left(1,5 \mathrm{~kg} \mathrm{~m}^{-2}\right)$ ao calor, nas temperaturas programadas

Outro aspecto térmico importante do sistema, visando ao controle de fitopatógenos, é apresentado na Figura 3, na qual se notam, na fase operacional 3, as curvas de temperatura (D) resultantes da superposição das curvas A (referencial), B e C, cujos pontos térmicos se igualam em toda a massa de água, devido a convecção forçada através das seções dos coletores solares que, além de equalizar as temperaturas da massa de água, impede também a formação de gradientes representativos de temperaturas $\left.\left(\mathrm{At}_{1} \mathrm{e} \mathrm{At}\right)_{2}\right)$ determinados entre as curvas referenciais $\mathrm{A}$ e as curvas $\mathrm{B}$ e $\mathrm{C}$, que ocorrem na fase operacional 2 , em pontos inferiores da massa líquida nas seções dos coletores.

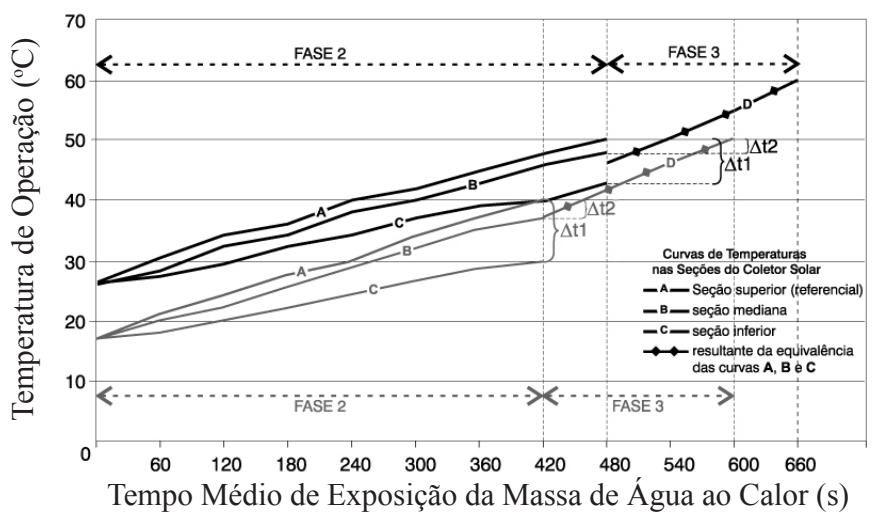

Figura 3. Curvas características de temperatura da massa de água no coletor solar $\left(1,5 \mathrm{~kg} \mathrm{~m}^{-2}\right)$ nas fases operacionais $2 \mathrm{e} 3$, correspondentes aos rendimentos térmicos $(\eta=50 \%$ e $\eta=54 \%$ ) obtidos durante o mês de junho, caracterizado como o de menor rendimento do sistema 
Tabela 1. Dados gerais médios mensais* obtidos nos testes de rendimento térmico do sistema

\begin{tabular}{|c|c|c|c|c|c|c|c|c|c|c|c|c|}
\hline $\begin{array}{l}\text { Data } \\
\text { Mês }\end{array}$ & $\begin{array}{c}\text { Teste CC } \\
\left(\mathrm{kg} \mathrm{m}^{-2}\right)\end{array}$ & $\begin{array}{l}\text { FTO } \\
\left({ }^{\circ} \mathrm{C}\right)\end{array}$ & $\begin{array}{l}\mathrm{Mt}_{1} \mathrm{D} \\
{ }^{\circ} \mathrm{C}^{* *}\end{array}$ & $\begin{array}{c}\mathrm{Mt}_{2} \mathrm{D} \\
{ }^{\circ} \mathrm{C}\end{array}$ & $\begin{array}{c}\text { DFT } \\
{ }^{\circ} \mathrm{C}\end{array}$ & $\begin{array}{l}\text { HR } \\
(\mathrm{KJ} n\end{array}$ & $\left.\frac{q u}{-2} h^{-1}\right)$ & $\begin{array}{l}\eta_{\mathrm{h}} \\
(\%)\end{array}$ & $\begin{array}{c}\mathrm{m}_{\mathrm{h}} \\
\left(\mathrm{kg} \mathrm{m}^{-2} \mathrm{~h}^{-1}\right)\end{array}$ & $\begin{array}{c}\mathrm{m}_{\mathrm{d}} \\
\left(\mathrm{kg} \mathrm{m}^{2} \mathrm{~d}^{-1}\right)\end{array}$ & $\begin{array}{c}\mathrm{m}_{\min } \\
\left(\mathrm{kg} \mathrm{m}^{-2} \min ^{-1}\right)\end{array}$ & $\begin{array}{l}\mathrm{T}_{\exp } \\
(\mathrm{min})\end{array}$ \\
\hline \multirow[t]{3}{*}{ Jan } & 1,5 & $50-24,4$ & 40 & 50 & 25,6 & 2314,69 & 1435,10 & 62 & 13,38 & 93,70 & 0,223 & 6,7 \\
\hline & 1,5 & $55-25,5$ & 45 & 55 & 29,5 & 2887,56 & 1538,15 & 55 & 12,85 & 90,00 & 0,211 & 7,7 \\
\hline & 1,5 & $60-25,0$ & 50 & 60 & 35,0 & 2386,80 & 1241,13 & 52 & 8,47 & 59,29 & 0,141 & 10,6 \\
\hline \multirow[t]{3}{*}{$\mathrm{Fev}$} & 1,5 & $50-25,7$ & 50 & 50 & 24,3 & 2416,46 & 1522,37 & 63 & 14,96 & 104,74 & 0,249 & 6,0 \\
\hline & 1,5 & $50-26,0$ & 45 & 55 & 29,0 & 2213,60 & 1239,61 & 56 & 11,66 & 81,54 & 0,194 & 7,4 \\
\hline & 1,5 & $60-26,0$ & 50 & 60 & 34,0 & 2015,64 & 1068,28 & 53 & 10,27 & 71,95 & 0,171 & 8,7 \\
\hline \multirow[t]{3}{*}{ Mar } & 1,5 & $50-27,0$ & 40 & 50 & 23,0 & 2433,09 & 1508,52 & 62 & 15,59 & 109,65 & 0,259 & 5,7 \\
\hline & 1,5 & $55-24,0$ & 45 & 55 & 31,0 & 2213,60 & 1217,48 & 55 & 9,37 & 65,66 & 0,156 & 9,6 \\
\hline & 1,5 & $60-27,0$ & 50 & 60 & 33,0 & 2015,64 & 1027,97 & 51 & 8,01 & 52,08 & 0,133 & 10,2 \\
\hline \multirow[t]{3}{*}{ Abril } & 1,5 & $50-22,0$ & 40 & 50 & 28,0 & 3089,84 & 1761,21 & 57 & 15,02 & 105,16 & 0,250 & 6,0 \\
\hline & 1,5 & $55-23,0$ & 45 & 55 & 32,0 & 2078,15 & 1133,00 & 54 & 8,45 & 59,19 & 0,140 & 10,6 \\
\hline & 1,5 & $60-23,0$ & 50 & 60 & 37,0 & 2099,84 & 1121,91 & 53 & 7,18 & 50,27 & 0,119 & 12,5 \\
\hline \multirow[t]{3}{*}{ Maio } & 1,5 & $50-22,5$ & 40 & 50 & 27,5 & 2433,09 & 1411,19 & 58 & 12,25 & 85,79 & 0,204 & 7,8 \\
\hline & 1,5 & $55-21,0$ & 45 & 55 & 34,0 & 2634,08 & 1369,72 & 52 & 9,62 & 67,35 & 0,160 & 9,3 \\
\hline & 1,5 & $60-20,0$ & 50 & 60 & 40,0 & 2625,18 & 1365,24 & 52 & 8,14 & 57,04 & 0,135 & 11,7 \\
\hline \multirow[t]{3}{*}{ Junh } & 1,5 & $50-18,0$ & 40 & 50 & 32,0 & 2180,12 & 1772,26 & 54 & 8,78 & 61,50 & 0,146 & 12,2 \\
\hline & 1,5 & $55-19,0$ & 45 & 55 & 36,0 & 2449,59 & 1117,78 & 52 & 8,34 & 58,40 & 0,139 & 10,8 \\
\hline & 1,5 & $60-20,6$ & 50 & 60 & 39,4 & 2700,46 & 1350,23 & 50 & 8,18 & 57,29 & 0,136 & 11,0 \\
\hline \multirow[t]{3}{*}{ Julh } & 1,5 & $50-20,0$ & 40 & 50 & 30,0 & 2091,60 & 1159,38 & 55 & 8,73 & 64,11 & 0,145 & 9,8 \\
\hline & 1,5 & $55-20,3$ & 45 & 55 & 34,7 & 2295,96 & 1490,32 & 53 & 8,19 & 57,35 & 0,136 & 10,9 \\
\hline & 1,5 & $60-24,0$ & 50 & 60 & 36,0 & 2055,70 & 1027,85 & 50 & 6,85 & 48,00 & 0,114 & 13,0 \\
\hline \multirow[t]{3}{*}{ Agos } & 1,5 & $50-18,0$ & 40 & 50 & 32,0 & 1995,98 & 1077,00 & 54 & 8,04 & 56,31 & 0,134 & 11,2 \\
\hline & 1,5 & $55-20,7$ & 45 & 55 & 32,3 & 1832,00 & 1004,35 & 53 & 7,17 & 50,25 & 0,119 & 12,5 \\
\hline & 1,5 & $60-22,7$ & 50 & 60 & 37,3 & 2272,82 & 1159,14 & 51 & 7,42 & 52,00 & 0,123 & 12,1 \\
\hline \multirow[t]{3}{*}{ Set } & 1,5 & $50-22,0$ & 40 & 50 & 28,0 & 2437,88 & 1413,97 & 58 & 12,05 & 84,43 & 0,200 & 7,4 \\
\hline & 1,5 & $55-23,3$ & 45 & 55 & 31,7 & 2358,93 & 1273,82 & 54 & 9,59 & 67,18 & 0,159 & 9,3 \\
\hline & 1,5 & $60-25,0$ & 50 & 60 & 35,0 & 2056,06 & 1069,15 & 52 & 8,08 & 56,57 & 0,134 & 11,1 \\
\hline \multirow[t]{3}{*}{ Out } & 1,5 & $50-24,8$ & 40 & 50 & 23,0 & 1641,60 & 1017,79 & 62 & 10,36 & 73,96 & 0,176 & 8,5 \\
\hline & 1,5 & $55-20,5$ & 45 & 55 & 34,5 & 2305,72 & 1192,97 & 52 & 8,30 & 58,10 & 0,138 & 10,8 \\
\hline & 1,5 & $60-20,0$ & 50 & 60 & 40,0 & 2277,61 & 1138,80 & 50 & 6,80 & 47,60 & 0,113 & 13,0 \\
\hline \multirow[t]{3}{*}{ Nov } & 1,5 & $50-27,0$ & 40 & 50 & 23,0 & 2403,79 & 1562,46 & 65 & 16,22 & 113,58 & 0,270 & 5,5 \\
\hline & 1,5 & $55-23,0$ & 45 & 55 & 32,0 & 2664,00 & 1438,56 & 54 & 10,73 & 75,16 & 0,178 & 8,3 \\
\hline & 1,5 & $60-26,3$ & 50 & 60 & 33,7 & 2086,20 & 1105,68 & 53 & 7,83 & 54,85 & 0,135 & 11,4 \\
\hline \multirow[t]{3}{*}{ Dez } & 1,5 & $50-25,0$ & 40 & 50 & 25,0 & 2340,14 & 1450,14 & 62 & 13,87 & 97,09 & 0,231 & 6,4 \\
\hline & 1,5 & $55-22,0$ & 45 & 55 & 33,0 & 2524,03 & 1524,45 & 56 & 10,89 & 79,28 & 0,181 & 8,2 \\
\hline & 1,5 & $60-24,7$ & 50 & 60 & 35,3 & 3076,66 & 1599,86 & 52 & 10,82 & 75,75 & 0,180 & 8,3 \\
\hline
\end{tabular}

* CC - Capacidade por carga da massa de água contida no coletor solar plano, igual a $1,5 \mathrm{~kg} \mathrm{~m}^{-2} ;$ FTO - Faixa de temperaturas de operação, abrangendo as temperaturas finais programadas e as temperaturas iniciais correspondentes à temperatura ambiente; Mt D - Monitor termostático diferencial da $1^{\text {a }}$ fase operacional do sistema; Mt $\mathrm{D}$ - Monitor termostático diferencial das operacionais (2) e (3) do sistema; DFT: Diferencial de temperatura de operação do sistema $(\Delta t)$; HR: Radiação solar média diária incidente no coletor; qu: Energia térmica útil coletada durante uma hora; $\eta$ - Eficiência térmica do sistema durante uma hora; $\mathrm{m}_{\mathrm{h}}$ - Massa de água processada no coletor solar, durante uma hora; $\mathrm{m}_{\mathrm{d}}$ - Massa de água processada no coletor solar, durante o período de sete horas de operação; $\mathrm{m}_{\min }$ - Massa de água processada no coletor solar, durante um minuto; $\mathrm{T}$ exp. - Tempo de exposição ao calor, nas faixas de temperatura programada, da massa de água de (1,5 kg m $\left.\mathrm{m}^{-2}\right)$ durante o período de processamento, correspondente à capacidade de carga do coletor solar.

Observação: ND - Número diário mensal de testes (15); Top - Tempo de operação diária do sistema (7 h); NT - Número médio mensal de repetições dos testes (150)

Esses gradientes são causados pelas correntes de convecção natural, normais nos sistemas convencionais de aquecimento solar da água, e criam zonas menos quentes nas seções inferiores dos coletores. Ressalta-se que, para a finalidade de desinfestação térmica da água, a utilização desses sistemas convencionais, já disponíveis para uso doméstico e outros fins, não seria eficiente, pois sem a equalização da temperatura essas zonas menos quentes poderiam permitir a sobrevivência de propágulos de fitopatógenos, que não seriam inativados.

Em termos de produção média diária de água processada (quantidade) em $\mathrm{kg} \mathrm{m}^{-2} \mathrm{~d}^{-1}$ de coletor solar o sistema testado apresentou, conforme a Figura 4, rendimento bem superior à média de $50 \mathrm{~kg} \mathrm{~m}^{-2} \mathrm{~d}^{-1}$ dos sistemas convencionais atualmente usados no Brasil, destinados principalmente à área doméstica.

Os testes realizados com os diversos fitopatógenos indicaram controle eficiente de todos eles. Verificou-se que, à exceção de Fusarium spp. e Fusarium oxysporum f.sp. vasinfectum, os quais foram inativados na faixa de temperatura de 55 a $60^{\circ} \mathrm{C}$, os demais fungos não sobreviveram além de 40 a $45^{\circ} \mathrm{C}$, com tempo médio de exposição de $2,5 \mathrm{~min}$, evidenciando-se a viabilidade prática da sua utilização.

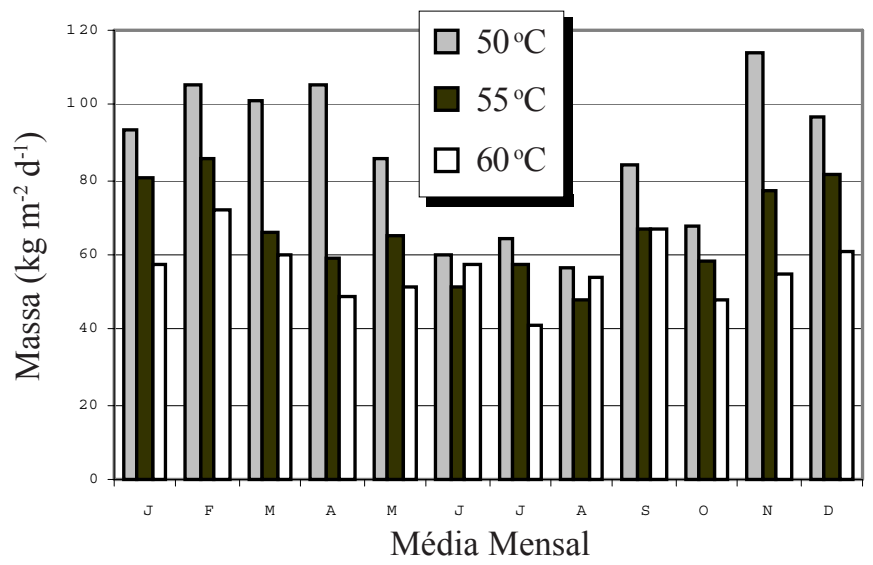

Figura 4. Produção média diária $(7 \mathrm{~h})$ de água processada, por unidade de área do coletor solar, nas temperaturas programadas 


\section{CONCLUSÕES}

1. Os resultados obtidos com o equipamento desenvolvido utilizando-se a energia solar como fonte de calor no aquecimento automatizado de água, mostraram que o desempenho do sistema é bastante eficiente e habilitado, podendo ser considerado promissor para tarefas de desinfestação da água de irrigação, visando ao controle de fitopatógenos, a exemplo da solarização, técnica que vem sendo usada com sucesso para controle de patógenos do solo, em pequenas e médias propriedades agrícolas.

2. Ficou comprovada a eficiência do sistema na eliminação do inóculo de fitopatógenos de importância econômica, como Botrytis cinerea, Colletotrichum fragariae, Fusarium sp., F. oxysporum f. sp. vasinfectum, Pythium sp. Verticillium dahliae e Rhizoctonia solani.

\section{AGRADECIMENTOS}

À FAPESP, pelo apoio financeiro para o desenvolvimento do projeto (Processo 98/12678-0); aos funcionários do CMAA/ IAC, Maria do Carmo Dorighello Gomes, pelo trabalho de digitação; Denival da Costa Silva, pelo apoio técnico; Elaine Sanches Zacharias, pelo auxílio na coleta e análise de dados; Varli José Dorighello e André Vinicius Favrim Franco, pelos trabalhos na área de informática.

\section{LITERATURA CITADA}

ABNT - Associação Brasileira de Normas Técnicas. Projeto de Norma - Método de ensaio de coletores solares planos para líquidos - determinação do rendimento térmico. Minuta 2. 1981.20p.

Armond, G.; Braga, C.A.S.; Bettiol, W; Ghini, R. Coletor solar plano para tratamento térmico do solo. O Agronômico, Campinas, v.42, n.3, p.185-189, 1990.

Batista Filho, B.D. Programa de energia solar no IPEN. In: Simpósio sobre Energia Solar, 2, 1981, São Paulo, SP. Anais... Publicação ACIESP nº 28, São Paulo, SP, 1981. p.10.
Bezerra, A.M. Aplicações práticas da energia solar. João Pessoa: Editora Universitária, UFPB. 1979, 127p.

CNP - Conselho Nacional de Petróleo-Revista Atualidades, v.3, n. $70,1980$.

Cochrane, V.W. Physiology of fungi. New York: John Wiley, $1958,524 \mathrm{p}$.

Deveral, B.J. The physical environment for fungal growth. In: Ainsworth, G.C.; Sussman, A .S. The fungi - An advanced treatise. vol. 1, New York: Academic Press. 1965. p.543-560.

Grech, N.M.; Rijkenberg, F.H.J. Injection of electrolytically generated chlorine into citrus microirrigation systems for the control of certain waterborne root pathogens. Plant Disease, St. Paul, v.76, n.2, p.457-461, 1992.

IPT - Instituto de Pesquisas Tecnológicas- Coletores solares planos para líquidos: Determinação do rendimento térmico, IPT/ FINEP/ INMETRO/ ABNT. Minuta 1. Setembro 1981. 20p.

Kpenzinger, A.; Corbela, O.D. Testes de eficiência de coletores solares na UTS. In: Congresso Brasileiro de Energia Solar, 2, 1981, Rio de Janeiro, RJ. Anais... Rio de Janeiro, RJ, 1981. $12 \mathrm{p}$.

Lunde, P.J. Solar thermal engineering: Space heating and hot water systems. New York: John Wiley, 1980. 612p.

Macedo, I.C. Conversão térmica de energia solar para processos industriais e domésticos. In: Simpósio sobre Energia Solar, 2, 1981, São Paulo. Anais... São Paulo, SP: ACIESP n.28, 1981.p.15.

Palz, W. Energia solar e fontes alternativas. São Paulo: Hemus Livraria Editora Ltda., 1981.358p.

Roa, G. Secador de produtos agropecuários por energia solar. In: Seminário sobre Tecnologia Aplicada e Sistemas de Energia Solar. Organização dos Estados Americanos, Universidade Autônoma de México, Jurica, Querêtaro, México, 1979, p.22.

Santos, L.A. Construção e avaliação de um coletor armazenador de energia solar, não convencional, para aquecimento de ar na secagem de produtos agrícolas. Campinas: UNICAMP, 1980. 102p. Dissertação Mestrado

Wolf, F.A; Wolf, F.J. The fungi. 1.ed. vol. 2. New York: John Willey, 1947.538p. 